\title{
Sciendo
}

Research Article

\section{Perceived Academic Stress among Undergraduate Students in a Nigerian University}

\author{
Osenweugwor Ngozi Aihie \\ Ph.D., Department of Educational Evaluation and Counselling Psychology, \\ Faculty of Education, University of Benin, Benin City, Nigeria \\ Blessing ljeoma Ohanaka \\ Ph.D., Department of Educational Evaluation and Counselling Psychology, \\ Faculty of Education, University of Benin, Benin City, Nigeria
}

Doi: 10.2478/jesr-2019-0013

\begin{abstract}
The purpose of the study was to investigate the levels of perceived academic stress among undergraduate students in a University in Nigeria. Purposive sampling was used to select three Faculties from the fourteen Faculties in the University. Simple random sampling was used to select 427 undergraduate students from the three Faculties to participate in the study. Data on perceived academic stress were collected with the aid of the Perceived Academic Stress Scale (PASS) which was adapted from Bedewy and Gabriel (2015) and re-validated for the study. Data collected for the study were analysed with descriptive and inferential statistics. The perceived academic stress levels of the respondents were compared on the basis of sex, age, level /year of study and Faculty /course of study. The hypotheses formulated for the study were tested at 0.05 level of significance. The findings revealed that male undergraduate students reported higher academic stress level than the females. Undergraduate students in the Faculty of Physical Sciences reported significantly higher academic stress levels than students in the Faculties of Education and Social Sciences. Final year students also reported higher academic stress than students in the first and middle years of study. There was no difference in perceived academic stress levels based on the age of the students. It was concluded that sex of student, level of study and course of study influence perception of academic stress among undergraduate students. Implications for Students' counselling were discussed.
\end{abstract}

Keywords: academic stress, undergraduate students, counselling

\section{Introduction}

Life is full of challenges for children and adults alike. Everyone faces stress in his or her own way. Stress is a natural event that people experience in their lives. According to the American Institute of Stress, it is a condition or feeling experienced when a person perceives that demand exceeds the personal and social resources the individual is able to mobilize ( as cited in Kania, 2014 ). Stress may be defined as any factor acting externally or internally, which makes adaptation to environment difficult and which induces increased effort on the part of the individual to maintain a state of equilibrium between self and the external environment (Richlin-Kinsky \& Hoe, 2003) Stress is a state of mental or emotional strain or suspense and it affects individuals irrespective of the developmental stage (Banerjee \& Chatterjee, 2012)

Academic stress refers to the unpleasant situations that occur due to the many demands made on the students or learners in the form of examinations, maintaining healthy and academic lives, competing with peers, meeting the academic expectations of teachers and parents as well as 
own academic expectations. Bisht (as cited in Lal,2014), defined academic stress as demands related to academics that tax or exceed the available resources (internal and external) as cognitively viewed by the student involved. According to her, academic stress reflects perceptions of an individual's academic frustration, academic conflict, academic pressure and academic anxiety. Bisht further defined the four components of academic stress as follows: academic frustration is a state of harm of some academic goals, academic conflict results from two or more incompatible responses to academic goals, academic pressure occurs when a student is under heavy demand of time and energy to meet academic goals and academic anxiety is an expression of apprehension of harm to academic goals (in La, 2014,p123). The academic environment can be highly competitive and students rely on their ability to cope to handle school related stress successfully. Mishra and Mckean (2000) presented a person-environment model for understanding stress in University students. The model suggests that individuals can consider stressful events as either challenging or demanding. When educational goals are perceived as challenging stress arises and creates a sense of competence thus enhancing learning capability. On the other hand, perceptions of educational goals as a threat brings stress which creates a feeling of hopelessness leading to lower academic achievement.

Stress is an unavoidable phenomenon in students' lives. In the academic setting, stress can arise from both academic and non-academic factors. These include socio-cultural and psychological attributes. Sources of stress in the academic setting may include difficulty with coping with a new environment, nature of as well as workload of course of study, relationship with other students, parental and teachers' expectations of students as well as own expectation of academic performance. Stress can have either a positive or negative effect on a student's academic performance depending on the severity. Minimal levels of stress can result in positive outcomes such as motivation and improved task performance while severe stress can result in anxiety, depression, and social dysfunctions. High levels of stress associated with poor academic performance (Sohail, 2013). Low stress however, may not necessarily result in good performance as under the circumstances, some students may perceive the task at hand as unchallenging and may easily get bored (Uchil, 2017). This may lead to poor academic performance. Stress affects students learning and academic performance negatively.as it can lead to anxiety, sleep problems and interpersonal conflicts. Majority of students with stress reported poor self-esteem and high depression (Baste \& Gadkari, 2014 ). Stress has been linked to indulgence in risky behaviour such as alcohol and other drugs consumption, unprotected sex, physical inactivity, poor eating and sleeping patterns among students (King, Vidowel \& Sigh, 2014; Bennett \& Holloway,2014 ) Also reported in students with academic stress are depression, anxiety, behavioural problems among other negative manifestations (Deb, Stoudl \& Sun,2015). In the same vein, fears of failure and negative evaluation of the future have been linked to incidences of depression which result from stress.

\subsection{Rationale for the study}

In the academic environment, too often much emphasis is placed on the acquisition of knowledge and academic achievement while neglecting the emotions or feelings of students as they learn. Students are vulnerable to problems associated with personal, social and academic domains and these invariably lead to academic stress and consequently poor academic performance among other negative results. Is self-reported academic stress influenced by sex of the students, age of the student, length of stay in the school and course of study? Understanding these issues will be of immense value in developing effective counselling intervention strategies to facilitate students' personal development and academic performance.

\subsection{Objectives of the study}

This study was carried out to determine the pattern of perceived academic stress among undergraduate students in a Nigerian University. The study specifically determined if there was a difference in the level of expressed academic stress between male and female students. The study further determined if level/year of study, Faculty/ course of study and age of the students had any significant influence on their levels of perceived academic stress. 


\subsection{Hypotheses}

The following null hypotheses were formulated to guide the study:

1. There is no significant difference in level of perceived academic stress between male and female undergraduate students.

2. There is no significant difference in the level of perceived academic stress between younger and older undergraduate students.

3. There is no significant difference in the level of perceived academic stress among undergraduate students in the three different Faculties.

4. There is no significant difference in the level of perceived academic stress among undergraduate students in the different levels of study.

\section{Literature Review}

Academic stress has been extensively researched. Different stressors have been identified in Literature and the effects of stress on academic achievement, physical and psychological wellbeing of students identified too. Academic stress is mental distress with respect to some anticipated frustration associated with academic failure or even the awareness of the possibility of such ( Gupta \& Khan as cited in Dhull \& Kumari, 2015 ).

Dwyer and Cumming (2001) found that in undergraduate students, stress was the most common among all health factors that influence academic achievement. Eweniyi (2009) observed that students suffer more stress than the rest of the population but seldom seek help. Academic stress can arise due to educational expectations of parents, teachers, burden of homework and assignments, examination systems among others. Students may experience academic stress from both their own expectations to excel as well as the expectations of their parents and teachers (Ang \& Huang in Dhull \& Kumari, 2015).Every parent wants his or her child to perform well academically and if possible be the best among the peers. Sometimes these expectations do not put into consideration the capabilities of the child. Parents thus burden their children with higher expectations which may lead to stress (Mishra, 2018). In the same vein, Essel \& Owusu (2017) opined that unrealistic parental expectation is a dominant stressor for students. The educational system may also play roles that lead to increased stress levels. Some of the sources of stress in the educational system include overcrowded lecture halls, inadequate resources and facilities long hours and expectations of rote learning (Deb, Strodl \& Sun 2015). Agolla and Ongori (as cited in Mishra, 2018) found that students reported experiencing high stress at University especially in preparation for examinations, competitions and mastering the syllabus within a short time. Other sources of academic stress include excessive workload unhealthy competition, time pressure (Hashmat, Hashmat \& Amanulla,2008,Batainesh,2013 Mishra, 2017), lack of finance and financial management, difficulties managing personal and academic life (Chemornas \& Shapiro, 2013) and students' poor academic self-perception (Hancock,2001). Carveth, Gesse and Mosse reported that Students complain of feeling stressed academically when it comes to facing examinations, grade competition and having too much information to study, yet insufficient time to master the knowledge (as cited in Elias,Ping \& Abdullahi,2011).

Excessive workload and homework make students tense and this may lead to inability to give proper time to different study related activities.(Mishra, 2018). Academic stress has negative impacts on academic achievement, physical and psychological wellbeing of students. Symptoms of stress include loss of energy, increased blood pressure, depressed mood, difficulty in concentration, impatience and nervousness. Stressed students are more likely to be poorly motivated, less productive, less safe at work and vulnerable to social vices like drug abuse and violence (Kio,Omeonu \&Agbede,2015). Winter and Yaffe (as cited in Mishra,2018) opined that high levels of stress during students' first year of study can make them susceptible to many social and psychological problems leading to low grades. Ekpeyong, Daniel \& Aribe (2013) suggested that individual variables that can influence one's response to stress include age, sex, physical ability, status, lifestyle, ethnicity among others. Some factors such as sex, age, year of study and course of study have been found to influence expressed level of stress among students. Jia and Loa 
((2018) report that freshmen (year one) undergraduates expressed higher academic stress than other students. This may be as a result of their being new in the school environment which they have to adjust to. They may therefore experience some degree of loneliness, anxiety, depression and even disorientation in the attempt to establish new social relationships, and at the same time trying to cope with the increasing academic demands (Dwyer \& Cummings, 2001). Elias, Ping and Abdullah (2011) found that final year students expressed higher levels of stress than other students. Another factor that has been found to influence expressed level of stress among students is the sex of the student. Reports on sex/gender differences in level of expressed academic stress have been equivocal. While some researchers found females reporting higher levels of academic stress than males( Ebrahim, 2016; Dhull \& Kumari,2015; Calvarcse,2015; Sulaiman, Sapin \& Abdullah,2009;Lo,2000' Mishrah \& Mc Kean,2000 ), others reported higher academic stress among males (Mishra,2018 ). In yet other researches (Yikaelo, Yemane \& Karvinen, 2018 Gonmei, \& Devendiran,2017;Farhan \& Khan,2015; Prabu,2015; Khan, Altaf \& Kauser,2013), sex was found to have no significant influence on expressed level of academic stress. Regarding the influence of course of study on expressed level of academic stress, Deepa (2016) found that students from Science stream experience more stress than students from the Humanities and Commerce streams. On the other hand, Reddy,Menon and Thattil (2018) in their study with undergraduate students from several streams found that students in Commerce stream had the highest level of academic stress and those in Humanities, the lowest. On the influence of age on academic stress of students, Khan, Altaf and Kausar (2016) found that younger students expressed higher academic stress than older students. Academic stress can be a risk factor that influences the quality of life of University students and can lead to poor academic achievement and dropping out of course.

\section{Methodology}

\subsection{Design of the study}

The study is a descriptive research. The major purpose of this type of research is observation and description of the state of affairs, for example, behaviour of a subject as it is. The main characteristic of the design is that the researcher has no control over the variables. In the present study, the perceived academic stress of the undergraduate students, males and females in three different Faculties and levels of study in the University was described. The researchers did not manipulate any the variables of the study. The survey method was employed in gathering data for the study.

\subsection{Sample of the study}

The sample of the study was made up of 427 randomly selected undergraduate students from three Faculties in a Nigerian University. Students were located in the lecture theatres just before the commencement of the second semester examinations. The Faculties of Education, Social Sciences and Physical Sciences were purposively selected for the study. Students in the Faculty of Education take courses in the Faculty of Social Sciences (Humanities) and Physical Sciences (Science) and the three Faculties offer four-year degree programmes. The sample was made up of 228 males (53.4\%) and $199(46.6 \%)$ females. $142(33.3 \%)$ of the students belong to the Faculty of Education, $159(37.2 \%)$, Faculty of Physical Sciences and $126(29.5 \%)$ belong to the Faculty of Social Sciences. $128(30 \%)$ of them are aged $16-19$ years and $229(70 \%)$ are aged 20 years and above. For the purpose of the study, there were three levels of study for the four year programmes.First year- 100 level made up of 140 students(32.8\% of the sample), middle years- 200 and 300 levels, made up of 172 students (40.3\% of the sample ) and Final year-400 level , made up of 115 students $(26.9 \%)$ of the sample).

\subsection{Instrument of the Study}

A 20-item questionnaire titled- Perception of Academic Stress Scale (PASS) was used to measure the level of expressed stress of the respondents. The instrument was adapted from Bedewy and Gabriel 
(2015). The original instrument is an 18-item instrument, designed to measure the perceived sources of stress, with responses on a 5-point likert scale ranging from strongly agree (5) to strongly disagree (1). The Face, content and convergent validity of the instrument were established and its internal consistency reliability determined using Crombach's alpha was 0.70. (Bedewy \& Gabriel, 2015).

Two new items were added to make the present instrument a 20-item scale and the responses were on a 4 -point -scale ranging from strongly agree (4) to strongly disagree (1) The internal consistency reliability of the present instrument was found to be 0.81 (Crombach's alpha).. The questionnaire was in two sections. Section A sought respondents' demographic information on age, sex, Faculty and Year of study while Section B was the 20-item perception of academic stress scale.

\subsection{Procedure}

The instrument was administered to the respondents in their lecture theatres just before the commencement of the second semester examinations and completed forms retrieved. The researchers explained the purpose of the study to the respondents and assured them of confidentiality of their responses. They were not required to state their names on the instrument. Data collected were collated and analysed using descriptive (means and standard deviation) and inferential statistics (t-test for independent samples and ANOVA). Alpha level was set at 0.05. The independent variables of the study were the Faculty/course of study which had three levels (Education, Social Sciences and Physical Sciences), Year of study which had three levels (Year one/100 level, middle years /200 and 300 levels and final year /400level.) and age which had two levels(16-19years (younger students) and 20years and above( -older students). The dependent variable of the study was the respondents' level of perceived academic stress.

\section{Results}

Table 1: Descriptive statistics of level of perceived academic stress of male and female undergraduate students

\begin{tabular}{lrrl}
\hline Sex & $\mathrm{N}$ & Mean & Std Deviation \\
\hline Male & 228 & 50.3612 & 7.45915 \\
Female & 199 & 48.7035 & 7.10286 \\
\hline
\end{tabular}

The results on table 1 show the mean score on perceived academic stress for males to be 50.3612 (standard deviation $=7.45915$ ) and the mean score for females to be 48.7035 (standard deviation $=7.10286$ ).

Hypothesis 1: There is no significant difference in level of perceived academic stress between male and female undergraduate students.

Table 2: Summary of the Independent Sample t-test on the differences between male and female undergraduate students' level of perceived academic stress.

\begin{tabular}{|c|c|c|c|c|c|c|c|}
\hline & \multicolumn{3}{|c|}{$\begin{array}{l}\text { Levene's Test for } \\
\text { Equality of variances }\end{array}$} & \multicolumn{3}{|c|}{ t-test for equality of means } & \multirow[b]{2}{*}{ Std Error diff } \\
\hline & $\mathrm{F}$ & Sig & $\mathrm{t}$ & df & Sig (2-tailed) & mean diff & \\
\hline Equal variances & & & & & & & \\
\hline Assumed & .059 & .808 & 2.340 & 424 & $.020^{*}$ & 1.65772 & .70842 \\
\hline $\begin{array}{l}\text { Equal variances } \\
\text { Not assumed }\end{array}$ & & & 2.348 & 421.091 & 1.019 & 1.65772 & .70614 \\
\hline
\end{tabular}

*Significant at 0.05 level 
The mean scores for males and females were compared using the independent sample t-test. The results displayed on table 2 show that the mean difference of 1.6577 was significant at 0.05 level of significance The hypothesis was therefore rejected and it is inferred that male undergraduates expressed significantly higher level of academic stress than their female counterparts.

Hypothesis 2: There is no significant difference in level of perceived academic stress of older and younger undergraduate students

Table 3: Means and standard deviation of the level of academic stress of younger and older undergraduate students.

\begin{tabular}{clcc}
\hline Age & $\mathrm{N}$ & Mean & Std Deviation \\
\hline 16-19 years & 128 & 49.7188 & 6.92017 \\
& & & \\
20years \& above & 299 & 49.5302 & 7.51435 \\
\hline
\end{tabular}

Table 3 reveals that the mean score on the level of perceived academic stress for younger undergraduates (ages 16-19 years) is $49.7188(S . D=6.92017)$ and for older undergraduates, the mean score is 49.5302 (S.D. $=7.51435)$

Table 4: Summary of Independent samples t-test on the difference in level of academic stress between younger and older undergraduates

\begin{tabular}{|c|c|c|c|c|c|c|c|}
\hline & \multicolumn{3}{|c|}{$\begin{array}{l}\text { Levene's Test for } \\
\text { Equality of variances }\end{array}$} & \multicolumn{3}{|c|}{ t-test for equality of means } & \multirow[b]{2}{*}{ Std Error diff } \\
\hline & $\mathrm{F}$ & Sig & $\mathrm{t}$ & df & Sig (2-tailed) & mean diff & \\
\hline \multicolumn{8}{|c|}{ Equal variances } \\
\hline Assumed & .955 & .329 & .243 & 424 & .808 & .18855 & .77584 \\
\hline \multicolumn{8}{|l|}{ Equal variances } \\
\hline Not assumed & & & .251 & 259.728 & .802 & .18855 & .75074 \\
\hline
\end{tabular}

Hypothesis 2 was tested using t-test of independent samples means. Results of the test are displayed on table 4 . The mean difference of .1885 was not significant at 0.05 level of significance. The hypothesis was thus upheld and it is inferred that there is no significant difference between younger and older undergraduates in level of perceived academic stress.

Hypothesis 3: There is no significant difference in perceived level of academic stress among the undergraduate students in the three different Faculties

Table 5: Mean and Standard deviation of expressed level of academic stress among undergraduates in the three different Faculties

\begin{tabular}{lllcr}
\hline Faculty & $\mathrm{N}$ & Mean & Std Deviation & Std Error \\
\hline Education & 142 & 49.0211 & 6.11644 & .51328 \\
Physical Sciences & 159 & 51.6962 & 7.41294 & .58974 \\
Social Sciences & 126 & 47.5974 & 7.84689 & .69906 \\
Total & 427 & 49.5869 & 7.33329 & .35530 \\
\hline
\end{tabular}

Results on Table 5 show the mean scores on the level of perceived academic stress of the undergraduates by their Faculties. Undergraduates in the Faculty of Physical Sciences have the highest mean score $(M=51.6962, S D=7.41294)$ followed by Education with a mean score of $(M=$ 49.0211, $S D=6.111644)$ and Social Sciences with a mean score o( $M=47.5974, S D=7.84689)$.. 
Table 6. Summary of ANOVA of the expressed levels of academic stress among Undergraduates in the three Faculties

\begin{tabular}{lccccc}
\hline & Sum of squares & df & Mean square & F & Sig \\
\hline Between Groups & 1256.226 & 2 & 628.113 & 12.301 & $.000^{*}$ \\
Within Groups & 21599.061 & 423 & 51.062 & & \\
Total & 22855.286 & 425 & & & \\
\hline
\end{tabular}

* significant at 0.05 level

Hypothesis 3 was tested at 0.05 level of significance using one- way analysis of variance statistics to determine if there is any significant difference in the mean scores of perceived academic stress among the undergraduates in the three Faculties. Results on table 6 reveal that there is a significant difference at 0.05 level. The null hypothesis was thus rejected and it is inferred that there is a significant difference in level of perceived academic stress among undergraduates in the three different Faculties. To ascertain the direction of the difference, a post hoc analysis using Scheffe method was done and the results are displayed on table 7 below.

Table 7. Multiple comparisons (Post hoc) of the differences in the level of expressed academic stress among undergraduate students in the three Faculties

\begin{tabular}{lllll}
\hline (I) Faculty & \multicolumn{1}{c}{ (J) Faculty } & $\begin{array}{l}\text { Mean diff } \\
\text { (I-J) }\end{array}$ & Std Error & Sig \\
\hline Education & Physical Sciences & -2.67508 & .82630 & $.006^{*}$ \\
& Social Sciences & 1.44176 & .87455 & .258 \\
& Education & 2.67508 & .82630 & $.006^{*}$ \\
Physical Sciences & Social Sciences & 4.11684 & .85348 & $.000^{*}$ \\
& Education & -1.44176 & .87455 & .258 \\
Social Sciences & Physical Sciences & -4.11684 & .85348 & $.000^{*}$ \\
\hline * The mean difference is significant at 0.05 level & &
\end{tabular}

The results on table 7 reveal a significant difference in level of perceived academic stress between undergraduates in the Faculties of Physical Sciences and Education and between undergraduates in the Faculties of Physical Science and Social Sciences, both cases in favour of the Faculty of Physical Sciences. The undergraduates in Faculty of Physical Sciences have significantly higher level of perceived academic stress than the undergraduates in the Faculties of Education and Social Sciences. There was no significant difference in level of expressed stress between undergraduates in the Faculties of Education and Social Sciences.

Hypothesis 4: There is no significant difference in the level of perceived academic stress among undergraduate students in the different levels of study.

Table 8: Descriptive Statistics showing the means and standard deviation of the levels of perceived academic stress among undergraduate students in the different levels of study.

\begin{tabular}{lccc}
\hline & $\mathrm{N}$ & Mean & Std Deviation \\
\hline 100 level & 140 & 48.3571 & 6.54599 \\
200 and 300levels & 172 & 49.7616 & 6.81983 \\
400 level & 115 & 50.8333 & 8.69942 \\
Total & 427 & 49.5869 & 7.33329 \\
\hline
\end{tabular}


The descriptive statistics displayed on Table 8 indicate that undergraduates in 400 level have the highest mean scores $(M=50.8333, S D=8.69942)$ of perceived academic stress followed by the undergraduates in 200 and 300 levels $(M=49.7616, S D=6.81983)$ and then, the undergraduates in 100 level $(M=48.3571, S D=6.54599)$. A one-way analysis of variance was done to determine if the difference among the three groups is statistically significant at 0.05 level of significance and the results displayed below on table 9 .

Table 9: Summary of ANOVA of the differences on level of expressed academic stress of undergraduates in the different levels of study

\begin{tabular}{lccccc}
\hline & Sum of squares & df & Mean square & F & Sig \\
\hline Between Groups & 394.083 & 2 & 197.042 & 3.711 & $.025^{*}$ \\
Within Groups & 22461.203 & 423 & 53.100 & & \\
Total & 22855.286 & 425 & & & \\
\hline
\end{tabular}

The results on table 9 show the $F$ value $=3.711$, d.f. $=2$ and $p$ value $=.025$. The $p$ value is less than the alpha level of .05. The null hypothesis was thus rejected. To ascertain the direction of the significant difference, a post-hoc analysis using Scheffe method was carried out and the result of the analysis is displayed on table 10 below.

Table 10: Multiple comparisons (Post hoc) of the differences in level of expressed academic stress of undergraduates in the different levels of study

\begin{tabular}{lllcc}
\hline (I)Level & (J) Level & $\begin{array}{c}\text { Mean diff } \\
(\mathrm{I}-\mathrm{J})\end{array}$ & Std Error & Sig \\
\hline 100 level & $200 \& 300$ levels & -1.40449 & .82946 & .240 \\
& 400 level & -2.47619 & .91928 & $.027^{*}$ \\
$200 \& 300$ levels & 100 level & -1.40449 & .82946 & .240 \\
& 400 level & -1.07171 & .88006 & .477 \\
400 level & 100 level & -2.47619 & .91928 & $.027^{*}$ \\
& $200 \& 300$ levels & -1.07171 & .88006 & .477 \\
\hline
\end{tabular}

* The mean difference is significant at 0.05 level

The results of the post-hoc analysis displayed on table 10 above indicate a statistically significant difference in the level of perceived academic stress between 400level (final year) undergraduates and the 100level (first year) undergraduate students. The students in the higher level of study expressed significantly higher level of academic stress than the first year students. No significant difference was found between the level of perceived academic stress of the 200 and 300 levels students and the other two groups.

\section{Discussion of Findings}

The results of the study revealed that there is a significant difference in the level of perceived academic stress based on sex of the respondents. The male undergraduates expressed significantly higher level of academic stress than the females. This result is at variance with the results of Ebrahim (2016), Dhull and Kumari (2015, Calvarese (2015 )and Sulaiman, Hassan and Sapin (2009) who found that female students reported higher academic stress than the males. The result does not also support Gonmei and Devendiran (2017), Yikealo, Yemane and Karvinen (2018), 
Farhan and Khan (2015) and Khan, Altaf and Kausar (2013)who made findings that suggest that sex does not have any influence on reported experience of stress among the students. The result of the study however corroborates Mishra(2018) who found that male B.Ed students reported higher academic stress than the females. That the males in this study expressed higher level of academic stress than the females may be due to the greater demand on the males in the patriarchal society to excel.. Parents' teachers' as well as the students' own expectation is that males be academically better than the females. Attempts to meet these expectations or pressure to perform not just better than others but particularly females, could lead to tension and stress. It might also be due to the tendency of males to be more casual and less serious about their studies than females and to procrastinate, as postulated by (Mishra,2018). Procrastination can lead to accumulated workload which in turn, leads to tension and stress. The result also revealed that there is no difference in level of expressed academic stress between younger and older undergraduate students. This result is an indication that age has no influence on expression of academic stress among the participants in the study. The result does not support Khan, Altaf and Kausar(2013), who found academic stress to be higher in younger students than older ones.

The study also found that the final year students perceived a significantly higher level of academic stress than the middle and first year students. This result may be due to the increased workload which includes research work and project writing in final year across Faculties. It may also be due to worry and anxiety about final results and future employment. The final year students are on the verge of graduation and failure in any course would entail "spilling" over to the next academic session. This result is in consonance with Elias, Ping and Abdullah (2011) among others who found that final year undergraduate students perceived higher levels of stress than students in other levels. The finding of the present study is however at variance with Jia and Loa (2018) and Khan, Altaf and Kausar(2013) who found that freshmen or first year students perceived higher level of academic stress than students in other levels. The results of the present study also showed that undergraduates in the Faculty of Physical Sciences had significantly higher level of academic stress than the students in the Faculties of Social Sciences and Education. This may be due to the nature and workload of the courses in the Physical Sciences which involve a lot of Practical work, field trips and report writing. This result corroborates the results of Deepa (2016) which showed that students in the Science Stream reported higher academic stress levels than students in the Humanities and Commerce. The results are also in consonance with Prabu (2015) who, worked with Secondary school students and found that students in Science subjects had higher levels of academic stress than Arts students.

\section{Conclusion}

From the results of the study, it can be concluded that perception of academic stress is influenced by sex of student, course of study and level or year of study among undergraduate students. It can also be inferred from the results of the study that perception of academic stress among undergraduate students is not influenced by age.

\section{Implications for Students' Counselling}

The results of the study have important implications for Students' counselling. The findings suggest that special attention be paid to male students, Final year students as well as students in the Faculty of Physical Sciences. In designing and implementation of Counselling interventions for stress, it is suggested that special attention be paid to the sources of stress among these groups of students in order to identify the stress -generating factors and manage or eliminate them. Stress Management as a topic, should also be included in the Orientation Programme usually organised for First Year students so that they can develop coping strategies early enough to forestall the negative effects of stress on academics and social life of the students. 


\section{References}

Banerjee,N. \& Chatterjee,I. (2012)Academic stress, suicidal ideation and mental well-being among 1st Semester and $2{ }^{\text {nd }}$ Semester Medical and Engineering and General Stream Students. Researchers World,73-80. Retrieved from https://search.proquest.com/docview/1816764514?pq-orgsite=gscolar.

Baste, V.S. \& Gadkan,J.V. (2014).Study of stress, self-esteem and depression in medical students and effects of music on perceived stress. Indian journal of physiology and pharmacology.58, 294-301

Batainceh, M.Z.(2013). Academic stress among undergraduate students: The case of Education Faculty at King Saud University. International Interdisciplinary journal of Education 2, 182-188.

Bedewy, D. \& Gabriel, A. (2015). Examining perceptions of academic stress and its sources among University students: The perception of Academic stress scale. Health Psychology Open, 2(2)

Bennett,T.H. \& Holloway, K.R. (2014). Drug misuse among university students in the U.K: Implications for prevention. Substance use and misuse.49 (4), 448-455

Busari, A.O. (2012).Evaluating the relationship between gender, age, depression and academic performance among adolescents. Scholarly Journal of Education 1(1), 6-12.

Calvarese, M. (2015). The effects of gender on stress factors : An exploratory study among University students. Social Sciences 4, 1177-1184. Available www.mdpi.com/journal/socsci.s

Chermonas, W.M. \& Shapiro, C. (2013). Stress, depression and anxiety among undergraduate nursing students. International Journal of Nursing School Scholarship.10 (1), 255-266

Deb, S., Strodl, E.\& Sun, J.(2015). Academic stress, parental pressure, anxiety and mental health among Indian high school students. International Journal of Psychology and Behavioural Sciences. 5(1), 25-34.

Deepa, S.K.(2016). Emotional intelligence and academic stress among College students. Education Quest: An international journal of Education and applied sciences.7 (3), 149-157.

Dhull,I.\& Kumari, S. (2015). Academic stress among adolescents in relation to gender. International Journal of Applied Research, 1(11), 394-396

Dwyer, A.L. \& Cummings,A.L. (2001). Stress, self-efficacy, social support and coping strategies in University students. Canadian Journal of Counselling. 35 (3), 205-220

Ebrahim, M. (2016). Perceived academic stress and its association with students' characteristics. Journal of Applied Medical Sciences. 5(4), 1-5

Ekpenyong, C.E., Daniel, N.E.\&Aribo, E.O.(2013). Associations between academic stressors, reaction to stress, coping strategies and musco skeletal disorders among college students. Ethiopian Journal of Health Sciences. 23 (2), 98-112

Elias, H.,Ping, W.S.\& Abdullah, M.C. (2011).Stress and academic achievement among undergraduates students in Universiti Pura, Malaysia. Procedia-Social and Behavioural Sciences. 29 (2011), 646-655.

Eweniyi, G.B.(2009). Stress management skills and University students' academic behaviour: Implications for counselling. The Social Sciences, scientific research and publishing company Medwell Journals 4(1), 139142.

Fan, F.M. \&Wang, J.Z.(2001). The study of qualityof psychological well-being among Beinjing students. Research in Education Tsinghia University 14(4), 26-32

Farhan, S. \& Khan, I (2015). Impacts of stress, self-esteem and gender factor on students' academic achievement. International journal of new trend in Education and their implications. 6(2), 154-167

Gonmei, J. \& Devendiran, C. (2017). Perceived stress and psychological factors of stress among youth. International Journal of academic research and development. 2 (6), $776-780$

Jia, Y.F. \& Loa, Y.T (2018). Prevalence and determinants of perceived stress among undergraduates of a Malaysian University. JUMMC.21 (1), 1-5.

Kania, S.K. (2013). The relationship between gender difference and stress The Huron University College journal of learning and motivation. 52 (1)article7.available at https://irlib.uwo.ca/hucjlm/vol52/iss $1 / 7$

Khan, M.J., Altaf, S. \& Kauser,H (2013) Effects of perceived academic stress on students' performance. FWU, Journal of Social Sciences. 7(2), 146-151.

King, K.A., Vidowel,R.A.\& Singh, A.(2014). Condoms, sex and STDs: Exploring sexual health issues among Asian Indian College students. Sexuality and Culture.18 (3), 649-663

Kio, J.O., Omeonu, P.E. \& Agbede, C.O.(2018). Assessment of stress levels among undergraduates in Nigeria: Implication for mental health policy. IOSR Journal of nursing and health science. 4(1),18-23.

Lal, K.(2014). Academic stress among adolescents in relation to intelligence and demographic factors. American International journal of research in Humanities, Arts and Social Sciences. 5 (1), 123-129.

Mishra, M. (2018). A comparative study on academic stress level of male and female B.Ed students. Indian Journal of health and well-being. 9(1), 131-135

Prabu, P.S. (2015). Astudy of academic stress among higher school students. International journal of Humanities and Social Science Innovation. 4(10),63-68. 
Reddy, K.J., Menon, K.R.\& Thattil,A. (2018). Academic stress and its sources among University students. Biomed Pharmacol journal.11 (1)

Richlin-Klonsky \& Hoe (2003). Sources and levels of stress among Ucla students. Students' affairs briefing 2

Sohail,N.(2013). Stress and academic performance among medical students. Journal of the College of physicians and surgeons, Pakistan.23, 67-71

Uchil, H.B.(2017). The effect of stress in students' performance. Stress management professional international journal 5(1)17-21

Wang, C.Y. (2005). Investigation on the stress state of undergraduates. Chinese Journal of Health Psychology, $13(4), 312-313$.

Wintre, M.G.\& Yaffe, M (2000). First year students' adjustment to University life as a function of relationship with parents. Journal of Adolescent research, 5(1), 9-37.

Yikealo,D., Yemane, B.\& Karvinen,I. (2018) The levels of academic and environmental stress among College students : A case in the College of Education. Open journal of Social Sciences.6, 40-57

Yussof, M.C.B., Rahim, A.F.A. \& Yaacob, M.J. (2010). Prevalence and sources of stress among Universiti Sains Malaysia medical students. Malaysian Journal of medical sciences, 17 (1),30-37 